\title{
The efficacy of high-dose penicillin G for pneumococcal pneumonia diagnosed based on initial comprehensive assessment at admission: an observational study
}

\author{
Junpei Komagamine* ${ }^{*}$
}

\begin{abstract}
Objectives: High-dose penicillin therapy is effective in approximately $90 \%$ of pneumococcal pneumonia cases diagnosed based on urinary pneumococcal antigen tests or Gram staining at admission. The efficacy of high-dose penicillin therapy for pneumococcal pneumonia diagnosed based on an initial comprehensive assessment comprising a syndromic approach, Gram staining of sputum and urinary pneumococcal antigen testing was investigated.

Results: Seventy adult patients diagnosed with pneumococcal pneumonia based on an initial comprehensive assessment and treated with high-dose penicillin $\mathrm{G}$ at admission were included. The median patient age was 76.5 years, and $37.1 \%$ of the patients were women. The urinary pneumococcal antigen test was positive in $67.1 \%$ of all patients, and Gram staining of sputum showed that gram-positive cocci were dominant in $58.6 \%$ of the patients. The primary outcome was treatment success based on vital signs until day 6 . Treatment with high-dose penicillin $\mathrm{G}$ was effective in $87.1 \%$ of the patients (95\% Cl 79.1-95.2\%), and the proportion of patients who received other antibiotics because of treatment failure with penicillin $\mathrm{G}$ was only $5.7 \%$. The efficacy of high-dose penicillin $\mathrm{G}$ treatment for pneumococcal pneumonia diagnosed based on a comprehensive assessment at admission may be comparable to that in previous reports.
\end{abstract}

Keywords: Community-acquired pneumonia, High-dose penicillin, Pathogen-targeted therapy, Streptococcus pneumoniae

\section{Introduction}

In initial assessments of pneumonia cases, it is often difficult to identify the causative organism based on clinical presentation and microbial examination [1-8], and most pneumonia guidelines thus recommend initial empirical treatment using broad-spectrum antibiotics $[9,10]$. However, previous randomized controlled trials have shown that pathogen-directed antibiotic therapy using narrowspectrum antibiotics is as effective as empirical antibiotic therapy for community-acquired pneumonia (CAP)

\footnotetext{
*Correspondence: junpei0919@yahoo.co.jp

Department of Internal Medicine, National Hospital Organization Tochigi Medical Center, 1-10-37, Nakatomatsuri, Utsunomiya, Tochigi 3208580, Japan
}

$[11,12]$. Given that adverse drug events occur more frequently with empirical treatment than with pathogendirected therapy $[11,13]$, the latter may be preferred.

Streptococcus pneumoniae is the most common causative organism of CAP requiring hospitalization in adults $[14,15]$. Previous studies have reported high treatment success rates with high-dose penicillins or amoxicillin for pneumococcal pneumonia diagnosed based on either urinary pneumococcal antigen test [16, 17] or Gram staining of sputum [13] at admission. However, little is known about the efficacy of strategies to diagnose pneumococcal pneumonia based on an initial comprehensive assessment combining clinical history, Gram staining of sputum and the urinary pneumococcal antigen test followed by treatment with high-dose penicillins as an

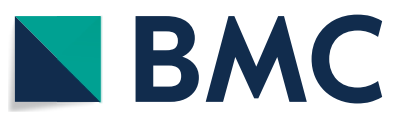

C The Author(s) 2018. This article is distributed under the terms of the Creative Commons Attribution 4.0 International License (http://creativecommons.org/licenses/by/4.0/), which permits unrestricted use, distribution, and reproduction in any medium, provided you give appropriate credit to the original author(s) and the source, provide a link to the Creative Commons license, and indicate if changes were made. The Creative Commons Public Domain Dedication waiver (http://creativecommons.org/ publicdomain/zero/1.0/) applies to the data made available in this article, unless otherwise stated. 
initial monotherapy. Thus, the aim of this research was to evaluate the efficacy of high-dose penicillin G for pneumococcal pneumonia diagnosed based on an initial comprehensive assessment at admission.

\section{Main text \\ Methods \\ Study design and setting}

This study was a retrospective observational study utilizing data obtained from electronic medical records of the National Hospital Organization Tochigi Medical Center, a 350-bed acute-care hospital in Japan. At that time, this hospital did not have an intensive care unit. This research was retrospectively registered as UMIN000025887 (January 28,2017$)$.

\section{Participants and inclusion criteria}

Patients aged 18 years or older who were admitted to the hospital for pneumonia and initially treated with high-dose penicillin G from April 2012 to May 2017 were included. During the study period, 78 patients who had received high-dose penicillin $G$ treatment for pneumonia were identified. Among them, eight patients did not initially receive penicillin $G$ treatment on the day of admission. Overall, 70 patients were included in the final analysis.

\section{Initial comprehensive assessment and treatment}

Beginning in April 2012, the hospital started pathogen-targeted therapy for hospitalized adult pneumonia patients in routine practice. When pneumonia is diagnosed by medical history, a physical examination, and a chest X-ray, expectorated sputum samples are collected by a nurse before administering antibiotics. If possible, physicians or laboratory technicians then perform and interpret sputum Gram staining at admission. Only good-quality sputum is used to determine the causative pathogen, although sputum quality is rather subjective and at the discretion of the principal physicians. When S. pneumoniae is clinically suspected to be the causative organism of pneumonia at the initial assessment, physicians perform urine antigen testing for S. pneumoniae. The physicians also prescribe either high-dose penicillin $\mathrm{G}$ or ampicillin at their discretion if one of the following is present: (1) gram-positive diplococci upon Gram staining; (2) positive urine antigen test; (3) sudden onset of fever, chest pain, lobar infiltrate, and leukocytosis at presentation (syndromic approach). Our syndromic approach is similar to a strategy used by a pathogen-directed therapy group in a previous study [11]. Patients who were treated with ampicillin based on the initial comprehensive assessment at admission were excluded because ampicillin is often prescribed empirically for aspiration pneumonia in this hospital.

\section{Microbiological investigations}

In routine practice, physicians perform sputum Gram staining and establish a sputum culture when possible at admission; during the diagnostic process, physicians also establish at least two sets of blood cultures. When S. pneumonia is clinically suspected to be the causative organism of pneumonia, physicians perform urine antigen tests using the BinaxNOW S. pneumoniae urinary antigen kit (Alere Scarborough, Inc. Scarborough, USA). The proportion of patients who were evaluated using these tests is shown in Additional file 1. The definitions of sputum quality for Gram staining, predominant morphotype, and etiology of pneumonia are also shown in Additional file 2 .

\section{Data collection and measurement}

Information on age, gender, symptoms, swallowing problems, past medical history, results of laboratory testing, and chest radiographs was retrieved from electronic medical records at admission. The pneumonia severity index (PSI) [18] and CURB-65 score $[9,19]$ at admission were calculated.

The primary outcome was the treatment success rate. Based on a previous study [12], treatment was judged to be successful when clinical stability was achieved between 2 and 6 days after admission (detailed information is provided in Additional file 2). Secondary outcomes included in-hospital mortality, 30-day mortality, 30-day readmission rate, and adverse drug events caused by penicillin G. Adverse drug events were determined based on documented physician diagnosis in medical records. The rate of change in the use of other intravenous antibiotics due to a lack of effectiveness against pneumonia was also assessed, as the clinical stability of pneumonia patients based on vital signs can be delayed, even if treatment is effective [20]. The last follow-up date was May 31, 2017.

\section{Statistical analysis}

Originally, this study was planned to target 100 patients, a size similar to pathogen-targeted therapy groups in previous randomized controlled trials [11, 12]. However, penicillin $G$ use for pneumococcal pneumonia at this hospital has declined since 2015, partly because ampicillin was more frequently selected as an initial antibiotic agent for pneumococcal pneumonia due to the inconvenience of prescribing penicillin $\mathrm{G}$. Therefore, the outcomes of 70 patients were analyzed.

Baseline characteristics were examined using descriptive statistics. Primary and secondary outcomes were calculated as the proportion of patients in whom 
those outcomes occurred in all patients. The Chi squared test was used to compare primary outcomes between subgroups of patients for whom pneumonia severity was classified based on PSI or CURB-65. The Chi squared test was also used for comparison of primary outcomes between pneumococcal pneumonia and pneumonia of undetermined etiology based on microbial investigation. Given that S. pneumoniae is the leading cause of pneumonia of unknown etiology [21, 22], a similar efficacy of treatment between each subgroup was hypothesized. These analyses were performed using Excel statistical software package version 2.11 (Bellcurve for Excel; Social Survey Research Information Co., Ltd., Tokyo, Japan); the level of significance was set at $5 \%$.

\section{Results}

The baseline characteristics of the patients are presented in Table 1 . The median age of the 70 patients was 76.5 years, and $26(37.1 \%)$ were women. The median PSI score of the pneumonia cases was 97.5 (Table 2).

In the initial assessment, the urinary pneumococcal antigen test was positive in $47(67.1 \%)$ of the 70 patients, and gram-positive cocci (GPC) were dominant upon Gram staining of sputum samples from 41 patients (58.6\%). Regarding the etiology of pneumonia based on the final results of microbial investigation, 46 cases $(65.7 \%)$ were Streptococcus pneumoniae, and 17 (24.3\%) were of an undetermined etiology. Among the 46 cases of presumed pneumococcal pneumonia, penicillin-susceptible S. pneumoniae (PSSP) and penicillin-intermediate resistant $S$. pneumoniae (PISP) were isolated from 20 patients and one patient, respectively. Penicillin-resistant S. pneumoniae (PRSP) was not isolated from any patient.

The treatment success rate was $87.1 \%$ (Table 3). The proportion of patients who were switched from penicillin $\mathrm{G}$ to other antibiotics due to pneumonia treatment failure (detailed information is described in an Additional file 2) was only 5.7\%. Two patients died in the hospital. During the study period, no drug adverse events caused by penicillin $G$ were documented. However, in one patient, penicillin $G$ was replaced by high-dose ampicillin because continuous infusion of penicillin $\mathrm{G}$ was judged by the principal physician to be difficult due to delirium. The treatment success rate did not differ significantly among the subgroups of patients classified according to pneumonia severity and was not different between pneumococcal pneumonia and pneumonia of undetermined etiology based on the final results of microbial investigations (detailed information is described in an Additional file 1).
Table 1 Baseline characteristics of 70 patients with pneumococcal pneumonia diagnosed based on an initial comprehensive assessment at admission

\begin{tabular}{|c|c|}
\hline Characteristics & $\begin{array}{l}\text { Total }^{\mathrm{a}} \\
\mathrm{N}=70\end{array}$ \\
\hline \multicolumn{2}{|l|}{ Patient characteristics } \\
\hline Age, median (IQR) & $76.5(68.0-85.8)$ \\
\hline Women & $26(37.1)$ \\
\hline Health-care associated & $11(15.7)$ \\
\hline Institutional resident & $11(15.7)$ \\
\hline Pneumococcal vaccination & $9(12.9)$ \\
\hline Number of medications, median (IQR) & $4(1-7)$ \\
\hline Immunosuppressive drug use $\mathrm{e}^{\mathrm{b}}$ & $5(7.1)$ \\
\hline Dysphagia $^{c}$ & $18(25.7)$ \\
\hline Prehospital antibiotic use & $23(32.9)$ \\
\hline \multicolumn{2}{|l|}{ Past medical history } \\
\hline Heart failure & $3(4.3)$ \\
\hline Ischemic heart disease ${ }^{d}$ & $3(4.3)$ \\
\hline Stroke or TIA & $14(20.0)$ \\
\hline Diabetes mellitus & $13(18.6)$ \\
\hline Chronic pulmonary disease $\mathrm{e}^{\mathrm{e}}$ & $18(25.7)$ \\
\hline Liver disease & $2(2.9)$ \\
\hline Dementia & $18(25.7)$ \\
\hline Chronic kidney disease & $6(8.6)$ \\
\hline Active cancer & $0(0.0)$ \\
\hline Current smoker, n (\%) & $7(10.0)$ \\
\hline Regular drinker, n (\%) & $20(28.6)$ \\
\hline \multicolumn{2}{|l|}{ Patient symptoms, $\mathrm{n}(\%)$} \\
\hline Acute onset ( $<4$ days) & $43(61.4)$ \\
\hline Chest pain & $18(25.7)$ \\
\hline Fever & $57(81.4)$ \\
\hline Chill & $14(20.0)$ \\
\hline Hemoptysis & $2(2.9)$ \\
\hline Cough & $49(70.0)$ \\
\hline Sputum & $40(57.1)$ \\
\hline Throat pain & $7(10.0)$ \\
\hline \multicolumn{2}{|l|}{ Vital signs, median (IQR) } \\
\hline Temperature, ${ }^{\circ} \mathrm{C}$ & $38.4(37.4-39.0)$ \\
\hline Systolic blood pressure, $\mathrm{mmHg}$ & $130.0(110.0-146.5)$ \\
\hline Diastolic blood pressure, $\mathrm{mmHg}$ & $70.5(63.0-84.3)$ \\
\hline Heart rate per minutes & $103.5(90.0-117.0)$ \\
\hline Respiratory rate per minutes ${ }^{f}$ & $24(20-28)$ \\
\hline Oxygen saturation at room air, \% & $91(88-94)$ \\
\hline
\end{tabular}

a Values are shown as numbers (percentages) unless stated otherwise

b This value includes corticosteroids, chemotherapy and immunosuppressive drugs

c Dysphagia was judged based on an assessment by speech therapists during a hospital stay

${ }^{d}$ Ischemic heart disease included angina, myocardial infarction and coronary artery graft surgery

e Chronic pulmonary disease included asthma, chronic obstructive pulmonary disease, and bronchiectasis

${ }^{f}$ Among 63 patients 
Table 2 Characteristics and management of 70 pneumococcal pneumonia cases diagnosed based on an initial comprehensive assessment at admission

\begin{tabular}{|c|c|}
\hline \multirow[t]{2}{*}{ Characteristics } & \multirow{2}{*}{$\begin{array}{l}\text { Total }^{\mathrm{a}} \\
\mathrm{N}=70\end{array}$} \\
\hline & \\
\hline \multicolumn{2}{|l|}{ Radiological characteristics } \\
\hline Bilateral infiltrate & $15(21.4)$ \\
\hline Upper lobe infiltrate & $10(14.3)$ \\
\hline Pleural effusion & $2(2.8)$ \\
\hline \multicolumn{2}{|l|}{ Microbial characteristics } \\
\hline \multicolumn{2}{|l|}{ Gram stain } \\
\hline GPC dominant (good-quality only) & $24(34.3)$ \\
\hline GPC dominant (regardless of quality) & $41(58.6)$ \\
\hline Not performed & $11(15.7)$ \\
\hline Urine pneumococcal antigen & $47(67.1)$ \\
\hline \multicolumn{2}{|l|}{ Blood culture } \\
\hline Streptococcus pneumoniae & $5(7.1)$ \\
\hline Streptococcus mitis & $1(1.4)$ \\
\hline Staphylococcus aureus & $1(1.4)$ \\
\hline \multicolumn{2}{|l|}{ Presumptive etiology } \\
\hline Undetermined & $17(24.3)$ \\
\hline Streptococcus pneumoniae & $46(65.7)$ \\
\hline Other pathogens & $7(10.0)^{c}$ \\
\hline \multicolumn{2}{|l|}{ Pneumonia severity } \\
\hline \multicolumn{2}{|l|}{ Pneumonia severity index } \\
\hline Total score, median (IQR) & $97.5(77.3-121.0)$ \\
\hline Class 1 & $5(7.1)$ \\
\hline Class 2 & $7(10.0)$ \\
\hline Class 3 & $19(27.1)$ \\
\hline Class 4 & $26(37.1)$ \\
\hline Class 5 & $13(18.6)$ \\
\hline \multicolumn{2}{|l|}{ CURB-65 } \\
\hline Low risk & $22(31.4)$ \\
\hline Intermediate risk & $23(32.9)$ \\
\hline High risk & $25(35.7)$ \\
\hline \multicolumn{2}{|l|}{ Management during hospital stay } \\
\hline \multicolumn{2}{|l|}{ Penicillin G treatment } \\
\hline Continuous infusion & $65(92.9)$ \\
\hline Duration, day, median (IQR) & $7.0(4.3-7.0)$ \\
\hline Switch to oral amoxicillin & $10(14.3)$ \\
\hline Macrolide combination & $0(0.0)$ \\
\hline Corticosteroid use & $2(2.9)$ \\
\hline Tracheal intubation & $1(1.4)$ \\
\hline Vasopressor use & $1(1.4)$ \\
\hline
\end{tabular}

a Values are shown as numbers (percentages) unless stated otherwise

b Sputum specimens were judged to be high quality if there were fewer than 10 squamous epithelial cells and greater than 10 polymorphonuclear cells per low-power field

' This value includes Haemophilus influenzae (four cases), Staphylococcus aureus (one case), Streptococcus mitis (one case), and Streptococcus agalactiae (one case)

\section{Discussion}

The results of this study showed that treatment with high-dose penicillin $G$ for pneumococcal pneumonia diagnosed based on a comprehensive initial assessment using a syndromic approach, Gram staining of sputum, and the urinary pneumococcal antigen test was effective in $87 \%$ of all cases. The results of the present study are similar to those of past studies, showing that pathogendirected therapy [11-13,16, 17] or empirical therapy with broad-spectrum antibiotic agents [11, 12, 20-25] is effective in $80-90 \%$ of CAP patients, even though the definition of treatment success differed somewhat from those of past studies [26]. Furthermore, adverse drug events in the present study were less frequent than in past studies that investigated the efficacy of broad-spectrum antibiotic agents for CAP patients [11, 12, 22-25]. Given that sputum specimens of high quality are not often obtained [14] and that the sensitivity of the urinary pneumococcal antigen test for diagnosis of pneumococcal pneumonia is inadequate [4], these findings are notable. Furthermore, this strategy may be preferable because drug adverse events occur in empirical therapy more frequently than in pathogen-targeted therapy $[11,13]$.

Nonetheless, these findings should be interpreted with caution given that this study lacked a control group, which is a major limitation. Although the baseline patient characteristics and the severity of pneumonias in the present study were not different from those in past studies of CAP $[11-13,16,17,20-25]$, the lack of a control group may confound the outcomes. Furthermore, the $95 \%$ confidence interval for the primary outcome was wide due to the small sample size, and its lower limit was less than $80 \%$. This efficacy rate might be unacceptable. Therefore, a well-designed study is needed to evaluate the efficacy of this strategy for pneumonia patients.

The efficacy of high-dose penicillin G therapy did not differ between pneumococcal pneumonia and pneumonia of undetermined etiology based on the final results of the microbial investigations. Given that penicillin $\mathrm{G}$ is a narrow-spectrum antibiotic agent, this finding supports past studies showing that $S$. pneumoniae is the leading cause of pneumonia of unknown etiology [27, 28], although some cases of pneumonia of undetermined etiology in this study might have been caused by viral infection [29].

De-escalation therapy after initial empirical therapy is uncommon in practice due to the undetermined etiology in most pneumonia patients [14]. Furthermore, relative to the practice of treating pneumonia patients with empirical antibiotic therapy, residents should be educated in the practice of estimating the suspected causative pathogen using clinical history and microbial tests [30, 31]. Therefore, further studies are warranted to identify an effective 
Table 3 Clinical outcomes of 70 pneumococcal pneumonia cases diagnosed based on clinical judgment at admission

\begin{tabular}{|c|c|}
\hline Characteristics & $\begin{array}{l}\text { Number of patients }(\%[95 \% \mathrm{Cl}]) \\
\text { Total, } \mathrm{N}=70\end{array}$ \\
\hline \multicolumn{2}{|l|}{ Primary outcome } \\
\hline Clinical success until day $6^{a}$ & 61 (87.1 [79.1 to 95.2]) \\
\hline \multicolumn{2}{|l|}{ Secondary outcomes } \\
\hline $\begin{array}{l}\text { Adverse drug events due to } \\
\text { penicillin } G\end{array}$ & $0(0.0[0.0$ to 0.0$])$ \\
\hline Switch to other antibiotics ${ }^{b}$ & $4(5.7[0.1 \text { to } 11.3])^{b}$ \\
\hline 30-day mortality & $1(1.4[-1.4 \text { to } 4.3])^{c}$ \\
\hline In-hospital death & $2(2.9[-1.1 \text { to } 6.9])^{c, d}$ \\
\hline Readmission within 30 days & $1(1.4[-1.4$ to 4.3$])$ \\
\hline \multicolumn{2}{|c|}{$\begin{array}{l}\text { a Clinical success was defined as the condition in which all the following } \\
\text { threshold values were achieved for a } 24-h \text { period: temperature, } \leq 37.2^{\circ} \mathrm{C} \text {; heart } \\
\text { rate, } \leq 100 \text { beats } / \mathrm{min} \text {; respiratory rate, } \leq 24 \text { breaths } / \mathrm{min} \text {; systolic blood pressure, } \\
\geq 90 \mathrm{mmHg} \text {; oxygen saturation, } \geq 90 \% \text { or arterial oxygen partial pressure, and } \\
\geq 60 \mathrm{mmHg} \text { when the patient was not receiving supplemental oxygen }\end{array}$} \\
\hline \multicolumn{2}{|c|}{$\begin{array}{l}\text { b This value includes cases in which penicillin } \mathrm{G} \text { was replaced by other } \\
\text { antibiotics because of pneumonia treatment failure (more detailed information } \\
\text { was described in an Additional file 2) }\end{array}$} \\
\hline \multicolumn{2}{|c|}{$\begin{array}{l}\text { c This patient died due to hospital-acquired pneumonia after recovery from } \\
\text { community-acquired pneumonia }\end{array}$} \\
\hline \multicolumn{2}{|c|}{$\begin{array}{l}\text { d This patient died due to the complication of acute respiratory distress } \\
\text { syndrome in influenza A pneumonia derived from an in-hospital influenza } \\
\text { outbreak }\end{array}$} \\
\hline
\end{tabular}

strategy for estimating the causative organism of pneumonia at an initial assessment and to treat the causative organism with narrow-spectrum antibiotic agents.

\section{Conclusions}

The efficacy of high-dose penicillin $G$ therapy for pneumococcal pneumonia diagnosed based on a comprehensive assessment at admission may be acceptable. Nonetheless, the results of this study should be interpreted with caution due to the lack of a control group. A well-designed study is needed to evaluate the efficacy of this strategy for pneumonia patients.

\section{Limitations}

First, this study had a retrospective observational design. Second, this study was limited to a single center and to hospitalized patients receiving high-dose penicillin $G$ therapy at admission; thus, the results may not be easily generalizable. These findings should be confirmed by future studies performed at other institutions. Third, it was unclear how often patients who were initially diagnosed with pneumococcal pneumonia at admission were treated with other antibiotic agents, such as ampicillin and ceftriaxone. It was also unclear whether the physicians prescribed penicillin G for pneumonia patients at admission because they truly suspected pneumococcal pneumonia. Fourth, PRSP was rarely isolated in this hospital. Therefore, these results may not be generalizable to other hospitals in which PRSP is more prevalent. Fifth, it is inconvenient to administer penicillin $G$ via intravenous infusion, and high-dose ampicillin might be preferable as an initial antibiotic agent for pneumococcal pneumonia. Sixth, the study hospital does not have an intensive care unit. Therefore, these findings might not be applicable to cases of very severe pneumococcal pneumonia. Seventh, data were collected from usual care. Given that adverse drug events are often unrecognized by physicians [32], these outcomes might be underestimated. Finally, a statistical analysis to investigate predictive factors associated with treatment success was not conducted.

\section{Additional files}

Additional file 1: Table S1. Enforcement and documentation rates of vital signs, microbial testing and imaging at admission. ${ }^{2}$ Sputum specimens were judged to be high quality if there were fewer than 10 squamous epithelial cells and greater than 10 polymorphonuclear cells per low-power field. Table S2. Clinical outcomes according to the severity of pneumonia based on CURB-65 and the pneumonia severity index. ${ }^{a}$ Clinical success was defined as the condition in which all the following threshold values were achieved for a $24-\mathrm{h}$ period: temperature, $\leq 37.2^{\circ} \mathrm{C}$; heart rate $\leq 100$ beats $/ \mathrm{min}$; respiratory rate $\leq 24$ breaths $/ \mathrm{min}$; systolic blood pressure, $\geq 90 \mathrm{mmHg}$; and oxygen saturation $\geq 90 \%$ or arterial oxygen partial pressure $\geq 60 \mathrm{mmHg}$ when the patient was not receiving supplemental oxygen. ${ }^{\mathrm{b}} \mathrm{C}$ mparison of outcomes between subgroups according to severity of pneumonia was performed using the Chi squared test. Table S3. Comparison of primary outcomes between subgroups according to the presumptive etiology of pneumonia based on the final results of microbial investigation. ${ }^{a}$ Clinical success was defined as the condition in which all the following threshold values were achieved for a 24-h period: temperature $\leq 37.2^{\circ} \mathrm{C}$; heart rate $\leq 100$ beats/min; respiratory rate $\leq 24$ breaths $/ \mathrm{min}$; systolic blood pressure, $\geq 90 \mathrm{mmHg}$; and oxygen saturation $\geq 90 \%$ or arterial oxygen partial pressure $\geq 60 \mathrm{mmHg}$ when the patient was not receiving supplemental oxygen. ${ }^{\mathrm{b}}$ Comparison of outcomes between subgroups was performed using the Chi squared test.

Additional file 2: Text S1. Definition of terms and outcomes used in this study. Text S2. Four cases in which penicillin $\mathrm{G}$ was replaced by other antibiotics because of treatment failure for pneumonia.

\section{Abbreviations}

CAP: community-acquired pneumonia; Cl: confidence interval; GPC: grampositive cocci; HCAP: healthcare-associated pneumonia; IQR: interquartile range; PRSP: penicillin-resistant S. pneumoniae; PISP: penicillin-intermediate resistant S. pneumoniae; PSI: pneumonia severity index; PSSP: penicillin-susceptible S. pneumoniae; TIA: transient ischemic attack.

\section{Authors' contributions}

JK designed the study, collected and analyzed the data, and wrote the main paper. The author read and approved the final manuscript.

\section{Acknowledgements}

Not applicable.

Competing interests

The author declares that there is no competing interests. 


\section{Availability of data and materials}

All data generated or analyzed during this study are included in this published article and its Additional files.

\section{Consent for publication}

Not applicable.

\section{Ethics approval and consent to participate}

This study was approved by the Medical Ethical Committee of Nationa Hospital Organization Tochigi Medical Center (No. 28-24) and was conducted in compliance with the guidelines of good clinical practice and the principles of the Declaration of Helsinki. Samples and data were collected as part of standard patient care, and the present study was a chart review without direct contact with patients. The need for individual informed consent was formally waived by the Medical Ethical Committee of the National Hospital Organization Tochigi Medical Center. However, according to Japanese Ethical Guidelines, a poster providing information about the collection and use of data for this study and the protection of personal information was displayed in the waiting room of the hospital.

\section{Funding}

None.

\section{Publisher's Note}

Springer Nature remains neutral with regard to jurisdictional claims in published maps and institutional affiliations.

\section{Received: 16 April 2018 Accepted: 18 June 2018}

Published online: 20 June 2018

\section{References}

1. Helms CM, Viner JP, Sturm RH, Renner ED, Johnson W. Comparative features of pneumococcal, mycoplasmal, and legionnaires' disease pneumonias. Ann Intern Med. 1979;90:543-7. https://doi. org/10.7326/0003-4819-90-4-543.

2. Woodhead MA, Macfarlane JT. Comparative clinical and laboratory features of legionella with pneumococcal and mycoplasma pneumonias. Br J Dis Chest. 1987;81(2):133-9. https://doi.org/10.1016/00070971(87)90130-6.

3. Farr BM, Kaiser DL, Harrison BDW, Connolly CK. Prediction of microbial aetiology at admission to hospital for pneumonia from the presenting clinical features. Thorax. 1989;44:1031-5. https://doi.org/10.1136/ thx.44.12.1031.

4. Sinclair A, Xie X, Teltscher M, Dendukuri N. Systematic review and metaanalysis of a urine-based pneumococcal antigen test for diagnosis of community-acquired pneumonia caused by Streptococcus pneumoniae. J Clin Microbiol. 2013;51:2303-10. https://doi.org/10.1128/JCM.00137-13.

5. Theerthakarai R, El-Halees W, Ismail M, Solis RA, Khan A. Nonvalue of the initial microbiological studies in the management of nonsevere community-acquired pneumonia. Chest. 2001;119:181-4. https://doi. org/10.1378/chest.119.1.181.

6. Rosón B, Carratalá J, Verdaguer R, Dorca J, Manresa F, Gudiol F. Prospective study of the usefulness of sputum gram stain in the initial approach to community-acquired pneumonia requiring hospitalization. Clin Infect Dis. 2000;31:869-74. https://doi.org/10.1086/318151.

7. Reed WW, Byrd GS, Gates RH Jr, Howard RS, Weaver MJ. Sputum gram's stain in community-acquired pneumococcal pneumonia. A meta-analysis. West J Med. 1996;165(4):197-204

8. Bohte R, Hermans J, van den Broek PJ. Early recognition of Streptococcus pneumoniae in patients with community-acquired pneumonia. Eur J Clin Microbiol Infect Dis. 1996;15:201-5. https://doi.org/10.1007/BF01591354.

9. Lim WS, Baudouin SV, George RC, Hill AT, Jamieson C, Le Jeune I, et al. British thoracic society guidelines for the management of community acquired pneumonia in adults: update 2009. Thorax. 2009;64(Suppl III):iii1-55. https://doi.org/10.1136/thx.2009.121434

10. Mandell LA, Wunderink RG, Anzueto A, Bartlett JG, Campbell GD, Dean $\mathrm{NC}$, et al. Infectious disease society of America/American thoracic society consensus guidelines on the management of community-acquired pneumonia in adults. Clin Infect Dis. 2007;44:S27-72. https://doi. org/10.1086/511159.

11. van der Eerden MM, Vlaspolder F, de Graaff CS, Groot T, Bronsveld W, Jansen HM, et al. Comparison between pathogen directed antibiotic treatment and empirical broad spectrum antibiotic treatment in patients with community acquired pneumonia: a prospective randomized study. Thorax. 2005:60:672-8. https://doi.org/10.1136/thx.2004.030411.

12. Falguera M, Ruiz-González A, Schoenenberger JA, Touzón C, Gázquez I, Galindo C, et al. Prospective, randomised study to compare empirical treatment versus targeted treatment on the basis of the urine antigen results in hospitalised patients with community-acquired pneumonia. Thorax. 2010;65:101-6. https://doi.org/10.1136/thx.2009.118588.

13. Fukuyama H, Yamashiro S, Kinjo K, Tamaki H, Kishaba T. Validation of sputum gram stain for treatment of community-acquired pneumonia and healthcare-associated pneumonia: a prospective observational study. BMC Infect Dis. 2014;14:534. https://doi.org/10.1186/1471-2334-14-534

14. Jain S, Self WH, Wunderink RG, Fakhran S, Balk R, Bramley AM, et al. Community-acquired pneumonia requiring hospitalization among US adults. N Engl J Med. 2015;373:415-27. https://doi.org/10.1056/NEJMo a1500245.

15. Saito A, Kohno S, Matsushima T, Watanabe A, Oizumi K, Yamaguchi $\mathrm{K}$, et al. Prospective multicenter study of the causative organisms of community-acquired pneumonia in adults in Japan. J Infect Chemother. 2006;12:63-9. https://doi.org/10.1007/s10156-005-0425-8.

16. Guchev IA, Yu VL, Sinopalnikov A, Klochkov OI, Kozlov RS, Stratchounski LS. Management of nonsevere pneumonia in military trainees with the urinary antigen test for Streptococcus pneumoniae: an innovative approach to target therapy. Clin Infect Dis. 2005;40:1608-16. https://doi. org/10.1086/429919.

17. Oka H, Ueda A, Watanuki Y, Tsukiji J, Kuroda H, Akashi S, et al. The efficacy of high-dose penicillin for community-acquired pneumonia diagnosed by pneumococcal urine antigen test. J Infect Chemother. 2009;15:108-12. https://doi.org/10.1007/s10156-009-0672-1.

18. Fine MJ, Auble TE, Yealy DM, Hanusa BH, Weissfeld LA, Singer DE, et al. A prediction rule to identify low-risk patients with community-acquired pneumonia. N Engl J Med. 1997;336:243-50. https://doi.org/10.1056/ NEJM199701233360402.

19. Lim WS, van der Eerden MM, Laing R, Boersma WG, Karalus N, Town Gl, et al. Defining community acquired pneumonia severity on presentation to hospital: an international derivation and validation study. Thorax. 2003;58:377-82. https://doi.org/10.1136/thorax.58.5.377.

20. Shefet D, Robenshtok E, Paul M, Leibovici L. Empirical atypical coverage for inpatients with community-acquired pneumonia: systematic review of randomized controlled trials. Arch Intern Med. 2005;165:1992-2000. https://doi.org/10.1001/archinte.165.17.1992.

21. Mills GD, Oehley MR, Arrol B. Effectiveness of $\beta$ lactam antibiotics compared with antibiotics active against atypical pathogens in non-severe community acquired pneumonia: meta-analysis. BMJ. 2005:330(7489):456. https://doi.org/10.1136/bmj.38334.591586.82.

22. Vardakas KZ, Siempos II, Grammatikos A, Athanassa Z, Korbila IP, Falagas ME. Respiratory fluoroquinolones for the treatment of communityacquired pneumonia: a meta-analysis of randomized controlled trials. CMAJ. 2008;179(12):1269-77. https://doi.org/10.1503/cmaj.080358.

23. Garin N, Genné D, Carballo S, Chuard C, Eich G, Hugli O, et al. $\beta$-lactam monotherapy vs $\beta$-lactam-macrolide combination treatment in moderately severe community-acquired pneumonia: a randomized noninferiority trial. JAMA Intern Med. 2014;174(12):1894-901. https://doi. org/10.1001/jamainternmed.2014.4887.

24. Postma DF, van Werkhoven $\mathrm{CH}$, van Elden LJ, Thijsen SF, Hoepelman Al, Kluytmans JA, et al. Antibiotic treatment strategies for communityacquired pneumonia in adults. N Engl J Med. 2015;372(14):1312-23. https ://doi.org/10.1056/NEJMoa1406330.

25. Eljaaly K, Alshehri S, Aljabri A, Abraham I, Mohajer MA, Kalil AC, et al. Clinical failure with and without empiric atypical bacteria coverage in hospitalized adults with community-acquired pneumonia: a systematic review and meta-analysis. BMC Infect Dis. 2017;17:385. https://doi.org/10.1186/ s12879-017-2495-5.

26. Aliberti S, Blasi F. Clinical stability versus clinical failure in patients with community-acquired pneumonia. Semin Respir Crit Care Med. 2012:33:284-91. https://doi.org/10.1055/s-0032-1315640. 
27. Ruiz-González A, Falguera M, Nogués A, Rubio-Caballero M. Is Streptococcus pneumoniae the leading cause of pneumonia of unknown etiology? A microbiologic study of lung aspirates in consecutive patients with community-acquired pneumonia. Am J Med. 1999;106:385-90. https:// doi.org/10.1016/S0002-9343(99)00050-9.

28. Musher DM, Montoya R, Wanahita A. Diagnostic value of microscopic examination of gram-stained sputum and sputum cultures in patients with bacteremic pneumococcal pneumonia. Clin Infect Dis. 2004;39:1659. https://doi.org/10.1086/421497.

29. Gadsby NJ, Russell CD, McHugh MP, Mark H, Morris AC, Laurenson IF, et al. Comprehensive molecular testing for respiratory pathogens in community-acquired pneumonia. Clin Infect Dis. 2016;62:817-23. https:// doi.org/10.1093/cid/civ1214.

30. Fujisaki R, Yamaoka T, Yamamura M, Kawakami S, Ono Y, Miyazawa Y, et al. Usefulness of gram-stained sputum obtained just after administration of antimicrobial agents as the earliest therapeutic indicator for evaluating the effectiveness of empiric therapy in community-acquired pneumonia caused by pneumococcus or Moraxella catarrhalis. J Infect Chemother. 2013;19:517-23. https://doi.org/10.1007/s10156-012-0475-7.

31. Ikai H, Morimoto T, Shimbo T, Imanaka Y, Koike K. Impact of postgraduate education on physician practice for community-acquired pneumonia. J Eval Clin Pract. 2012;18:389-95. https://doi.org/10.111 1/j.1365-2753.2010.01594.x.

32. Hohl CM, Zed PJ, Brubacher JR, Abu-Laban RB, Loewen PS, Purssell RA. Do emergency physicians attribute drug-related emergency department visits to mdecation-related problems? Ann Emerg Med. 2010;55:493-502. https://doi.org/10.1016/j.annemergmed.2009.10.008.
Ready to submit your research? Choose BMC and benefit from:

- fast, convenient online submission

- thorough peer review by experienced researchers in your field

- rapid publication on acceptance

- support for research data, including large and complex data types

- gold Open Access which fosters wider collaboration and increased citations

- maximum visibility for your research: over $100 \mathrm{M}$ website views per year

At BMC, research is always in progress.

Learn more biomedcentral.com/submissions 